\title{
DIA DE CAMPO: IMPORTÂNCIA DO CULTIVO DE PRODUTOS BIOFORTIFICADOS NA COMUNIDADE BARRA DO SACO NO MUNICÍPIO DE CODÓ-MA
}

\section{FIELD DAY: IMPORTANCE OF CULTIVATION OF BIOFORTIFIED PRODUCTS IN THE BARRA DO SACO COMMUNITY IN THE MUNICIPALITY OF CODÓ-MA}

Natan Ferreira de Santana ${ }^{1}$; João Paulo da Silva Sousa ${ }^{2}$; Elilson Santa Brígida de Souza ${ }^{3}$; Natacha Ferreira de Santana ${ }^{4}$; Maiany Gonçalves de Carvalho ${ }^{5}$

DOI: $\underline{\text { https://doi.org/10.31692/978-65-991061-7-0.471-713 }}$

\section{INTRODUÇÃO}

O processo de biofortificação é feito com o cruzamento de plantas da mesma espécie, conhecido como melhoramento genético convencional, gerando cultivares mais nutritivas. Além da qualidade nutricional, são também incorporadas boas qualidades agronômicas, como produtividade, resistência à seca e pragas, etc. (EMBRAPA, 2017).

O trabalho teve como objetivo fazer um relato sobre um dia campo referente às técnicas de cultivo e manejo do sistema BioFORT, realizado na comunidade Barra do Saco (Codó-MA) e a implicação do mesmo para aprendizagem de alunos da disciplina de agricultura geral, do curso de Licenciatura em Ciências Agrárias e da comunidade em geral.

\section{RELATO DE EXPERIÊNCIA}

O dia de campo sobre cultivares bioforticados ocorreu no dia 20 de setembro de 2017, na propriedade do Senhor Onias Vieira de Santana (Baxote), que fica localizado na comunidade Barra do Saco, no município de Codó, Maranhão. A participação no evento foi uma proposta do curso de Licenciatura em Ciências Agrárias, com intuito de verificar na pratica os diferentes tipos de produção dos produtos biofortificados. O proprietário realiza o evento sobre os produtos bioFORT desde o ano de 2015, assim, é pioneiro no plantio dessas cultivares na região dos cocais maranhense, e conta com a parceria da Embrapa Meio Norte, da Embrapa Cocais, da Agência Estadual de Pesquisa Agropecuária e de Extensão Rural do Maranhão-Agerp/Codó e Secretaria Estadual de Agricultura.

O evento buscou repassar para os agricultores da região, para os alunos e para a comunidade em geral, novas técnicas acerca das cultivares, manejos e métodos de plantio dos

\footnotetext{
${ }^{1}$ Licenciatura em Ciências Agrarias, IFMA- CAMPUS CODÓ, nattanvqr@gmail.com

${ }^{2}$ Licenciatura em Ciências Agrarias, IFMA- CAMPUS CODÓ, joaopauloneto1.00@gmail.com

${ }^{3}$ Licenciatura em Ciências Agrarias, IFMA- CAMPUS CODÓ, desouzaelilson@gmail.com

${ }^{4}$ Bacharelado em agronomia, IFMA- CAMPUS CODÓ, natachaagro@gmail.com

${ }^{5}$ Professora Mestra, IFMA-CAMPUS CODÓ, maiany.carvalho@ifma.edu.br
} 
produtos biofortificadas. Os técnicos juntamente com o agricultor Baxote, falaram sobre importância das principais cultivares que são plantadas na área como: o Milho (BRS 4104), Batata Doce (Beauregard) e Feijão-caupi (Aracê) desenvolvidos pela Embrapa, como mostra as imagens abaixo.

Imagens 1: Visita ao campo de produção, com palestra do técnico da Embrapa, (A); Visita ao local de produção do milho bioFORT, (B); Visita a área de produção do feijão bioFORT, (C); Proprietário divulgando e comercializando seus produtos bioFORT, (D). Fonte: Própria
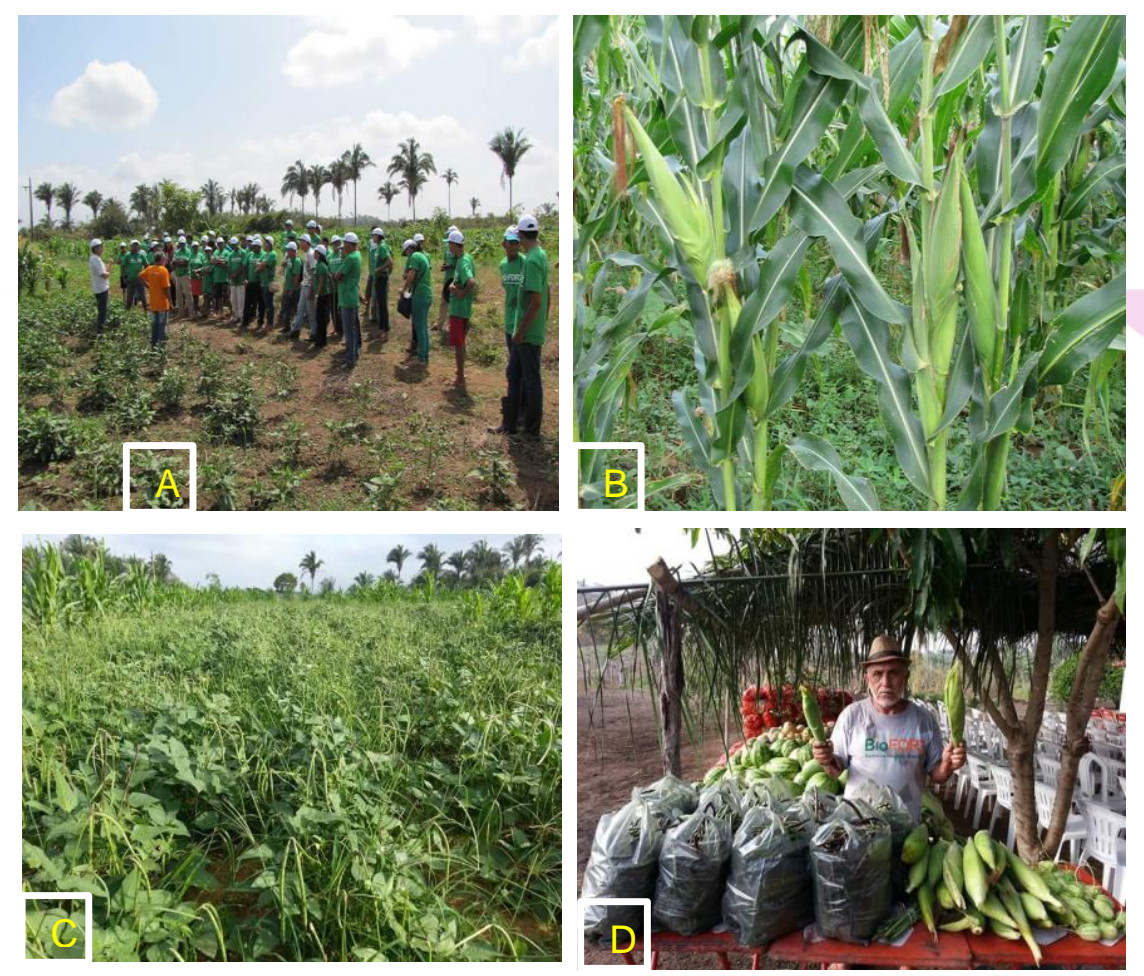

\section{CONSIDERAÇÕES}

O dia de campo mostrou-se relevante para os participantes, pois foi abordada a importância do cultivo dos produtos biofortificados, com isso os pequenos agricultores e alunos que prestigiaram o evento, conheceram as técnicas, manejos e dificuldades de produção que o homem do campo enfrenta diariamente, conheceram sobre esses alimentos mais ricos em nutrientes e que garantem a segurança alimentar. As práticas demonstradas proporcionaram obter informações a respeito das variedades plantadas na propriedade que sediava o evento, norteando a importância da prática adequada de plantio, manejo, colheita e os possíveis canais de comercialização. Assim, os agricultores convidados tiveram a oportunidade de tirar suas dúvidas e obter conhecimento para levar para suas propriedades, e oportunizou a troca de experiências entre o proprietário do local e os alunos do curso de licenciatura em ciências agrárias. 


\section{REFERÊNCIAS}

EMBRAPA, Alimentos Biofortificados, Dia de campo sobre culturas biofortificadas será realizado em Codó-MA, São Luis-MA, 2017.

EMBRAPA, Alimento Biofortificados, Milho Biofortificado, Disponível em: $<$ www.embrapa.br/busca-de-noticias/-/noticia/1492136/milho-biofortificado-seralancado-pela-embrapa>. Acesso em: 10 de out. 2018.

EMBRAPA, Alimento Biofortificados, Batata Biofortificado. Disponível em:<www.embrapa.br/busca-de-solucoes-tecnologicas/-/produto-servico/602/batata-docebeauregard $>$. Acesso em: 09 de out.2018.

EMBRAPA, Alimento Biofortificados, Feijão Biofortificado. Disponível em:< www.embrapa.br/busca-de-publicacoes/-/publicacao/1031579/biofortificacao-do-feijaocaupi.>. Acesso em: 08 de out.2018. 